\title{
Correction to: Identification of the functional role of peroxiredoxin 6 in the progression of breast cancer
}

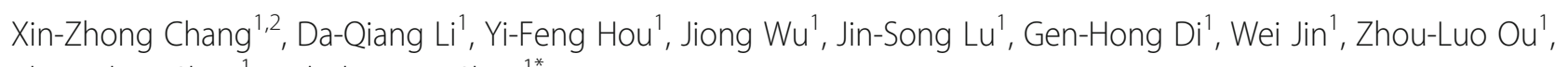
Zhen-Zhou Shen ${ }^{1}$ and Zhi-Ming Shao ${ }^{1 *}$

\section{Correction}

After the publication of this work [1] an error in Fig. 1c was brought to our attention: the Western blots for PRDX6 and $\beta$-actin were similar to those shown in lanes 5-6 of Fig. 4g. To verify these findings, we have repeated this experiment and the results are shown in a new Fig. 1c below. The repeated experimental results are consistent with the previously reported findings in the original study [1] and the functional role for PRDX6 in malignant progression of human cancer including breast cancer has been widely documented and recognized in numerous other studies [2]. We apologize for the error. However, this correction does not affect the conclusions of the article.

\begin{abstract}
Author details
'Breast Cancer Institute, Cancer Hospital, Department of Oncology, Shanghai Medical College, Institutes of Biomedical Science, Fudan University, Shanghai 200032, People's Republic of China. ${ }^{2}$ Tianjin Medical University Cancer Institute and Hospital, Hexi district, Tianjin 300060, China.
\end{abstract}

Published online: 02 July 2018

\section{References}

1. Shao $Z$, et al. Identification of the functional role of peroxiredoxin 6 in the progression of breast cancer. Breast Cancer Res. 2007;9:R76.

2. Coppa A, et al. The role of peroxiredoxins in cancer. Mol Clin Oncol. 2017; 6(2):139-53.

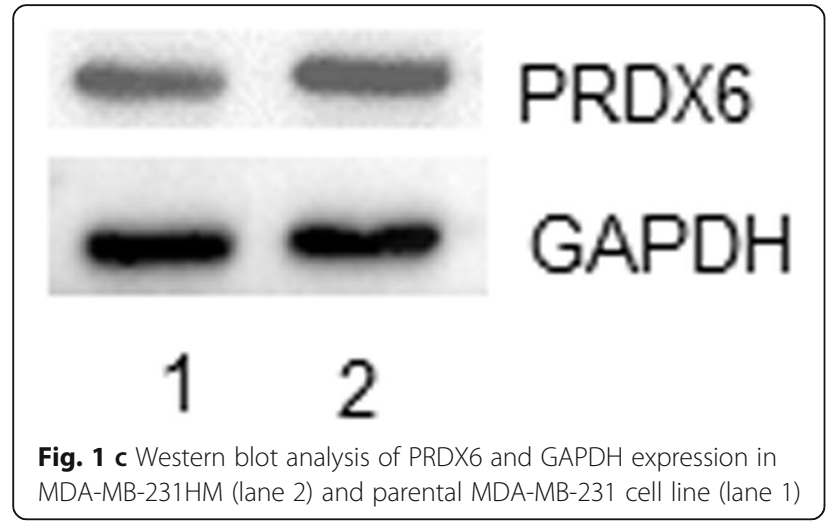

*Correspondence: zhimingshao@yahoo.com

${ }^{1}$ Breast Cancer Institute, Cancer Hospital, Department of Oncology, Shanghai Medical College, Institutes of Biomedical Science, Fudan University, Shanghai 200032, People's Republic of China (c) The Author(s). 2018 Open Access This article is distributed under the terms of the Creative Commons Attribution 4.0 International License (http://creativecommons.org/licenses/by/4.0/), which permits unrestricted use, distribution, and reproduction in any medium, provided you give appropriate credit to the original author(s) and the source, provide a link to the Creative Commons license, and indicate if changes were made. The Creative Commons Public Domain Dedication waiver (http://creativecommons.org/publicdomain/zero/1.0/) applies to the data made available in this article, unless otherwise stated. 